\title{
Sipakatau, Sipakainge, Sipakalebbi: Sebuah Nilai Budaya untuk Upaya Pencegahan Bullying dengan Memaksimalkan Peran Bystander
}

\section{Sipakatau, Sipakainge, Sipakalebbi: A Cultural Values for Bullying Prevention with Optimalized Bystanders Role}

\author{
Andi Halima ${ }^{1}$, Asniar Khumas ${ }^{1}$, Kurniati Zainuddin ${ }^{1}$ \\ ${ }^{1}$ Universitas Negeri Makassar \\ andihalima@unm.ac.id
}

\begin{abstract}
Abstrak
Bystander berperan penting pada terulang tidaknya episode bullying di sekolah. Bystander perlu dilibatkan secara aktif dalam upaya pencegahan bullying. Pencegahan bullying perlu sensitif budaya. Nilai Sipakatau, Sipakainge, Sipakalebbi dalam budaya Bugis sejalan dengan nilai anti-bullying. Penelitian ini merupakan studi awal yang bertujuan untuk mengetahui bagaimana nilai budaya Sipakatau, Sipakalebbi, Sipakainge mendorong bystander bertindak aktif dan bagaimana nilai tersebut diterapkan dalam pergaulan di sekolah. Prosedur sosiometri dan ilustrasi peran bullying digunakan untuk mengidentifikasi peran bystander. Penelitian ini menggunakan metode kualitatif dengan prosedur wawancara semi terstruktur dan observasi non partisipatif terhadap empat bystander yang berperan membela pada situasi bullying. Hasil penelitian menunjukkan bahwa sikap saling menghargai, mengingatkan, dan menghormati muncul dalam pergaulan sesama teman didasari oleh nilai-nilai agama dan dari nilai budaya Sipakatau, Sipakainge, Sipakalebbi yang disosialisasikan dalam budaya Bugis. Nilai karakter dalam konsep Sipakatau, Sipakainge, Sipakalebbi telah diterapkan pada strategi yang digunakan bystander untuk melakukan tindakan pencegahan bullying. Temuan ini dapat menjadi masukan untuk mempromosikan nilai-nilai agama dan budaya sebagai upaya pencegahan bullying di sekolah.
\end{abstract}

Kata kunci: Pencegahan Bullying, Sipakatau, Sipakalebbi, Sipakainge, Bystander.

\begin{abstract}
Bystander plays an important role in the recurrence of bullying episodes, so that they needs to be empowered in order to prevent bullying. bullying prevention need to be culturally sensitive. The values of Sipakatau, Sipakalebbi, Sipakainge appear to be in line with anti-bullying value. This study is a preliminary studies that aimed to find whether those cultural values could encourage the bystander to be actively involved and how to apply them in the social relationships. Therefore, the study used a qualitative method with a semi-structured interview and non participative observation on four bullying defenders. The result showed that the values of Sipakatau, Sipakalebbi, Sipakainge arose in religious values that socialized within family. Sipakatau, Sipakalebbi, Sipakainge were appeared as strategies to intervene bullying. These findings can be suggested to promote the religious and cultural-based association value as a prevention of school bullying.
\end{abstract}

Keyword: Bullying prevention, Sipakatau, Sipakainge, Sipakalebbi, Bystander 


\section{Pendahuluan}

Kasus bullying di Indonesia termasuk dalam kategori darurat (Komnas Ham RI, 2017). Kasus bullying terjadi hampir di setiap sekolah. Data KPAI bidang pendidikan, terdapat $14,3 \%$ anak pelaku tawuran, 19,3\% korban bullying, 22,4\% pelaku kekerasan, dan 25,5\% kasus bullying, 18,7\% korban. Pada Hari anak nasional, KPAI mengkampanyekan stop bullying dan mensosialisasikan dampak buruk bullying bagi tumbuh kembang anak (Tempo.co.id, 2018). KPAI mengemukakan bahwa berdasarkan data yang diperoleh dalam kurun waktu 9 tahun, dari 2011 sampai 2019, terdapat 37.381 pengaduan kekerasan terhadap anak, untuk kasus bullying mencapai hingga 2.473 laporan dan terus mengalami peningkatan (KPAI.go.id, 2020). Bullying berdampak buruk bagi kesehatan fisik dan psikis individu. Dampak fisik pada korban bullying yang ditemukan berupa luka fisik disebabkan memperoleh tendangan, pukulan, dorongan dan secara psikis berupa rendahnya rasa percaya diri, perasaan tidak aman, takut bersosialisasi, dan sulit berkonsentrasi dalam belajar (Amnda et al., 2020). Bullying dapat membuat remaja menjadi merasa sedih, marah, rendah diri dan membenci diri sendiri (Zakiyah et al., 2018). Berdasarkan kasus tersebut, bullying merupakan tindakan yang berdampak buruk dan perlu ditanggapi serius oleh semua pihak.

Bullying di sekolah seringkali dijelaskan sebagai fenomena kelompok yang melibatkan triadic process, yakni pelaku, korban, dan saksi. Saksi merupakan pihak terbanyak yang berperan penting dalam berlanjut atau tidaknya episode bullying di sekolah. Faktanya $85 \%$ pelaku mulai menyerang korban, pada situasi dan tempat yang dihadiri oleh teman sebaya (Lynn Hawkins et al., 2001). Kehadiran bystander pada situasi bullying berkontribusi terhadap peningkatan intensitas bullying sebab dinilai mendukung pelaku (Halimah et al., 2015).

Individu yang menyaksikan atau mengetahui kejadian bullying, disebut dengan istilah bystander bullying. Bystander berperan penting dalam situasi bullying di sekolah, khususnya peer bystander, sebab teman sebaya memberi ruang untuk bullying bernafas dan menyebar namun meski terdapat satu teman yang baik berada di pihak korban, hal tersebut dapat membantu mengurangi konsekuensi yang menyakitkan dari bullying (Rodkin, 2012). Ketika teman sebaya melakukan intervensi melawan bullying, 57\% episode bullying berhenti dalam waktu 10 detik (Lynn Hawkins et al., 2001).

Pada suku Bugis di Sulawesi Selatan, dikenal sebuah nilai budaya 'Sipakatau, Sipakainge, Sipakalebbi. Sikap ini mengajarkan pada individu bagaimana mencapai kesuksesan dan berhubungan dengan sesama manusia, sebab kesuksesan tidak akan bisa diraih tanpa kerjasama dan interaksi dengan orang-orang di lingkungannya. Nilai tersebut menekankan pada upaya saling memanusiakan, saling mengingatkan, dan saling menghargai. Penerapan dari ketiga sikap tersebut dianggap akan memudahkan urusan individu. Sipakatau adalah cerminan untuk selalu saling menghormati dan tidak saling bermusuhan, Sipakainge adalah tindakan untuk selalu saling mengingatkan, saling menegur, saling mengevaluasi, dan saling membimbing kepada hal-hal yang benar, Sipakalebbi adalah sebuah gambaran untuk menjalani kehidupan dalam bermasyarakat untuk selalu saling menghargai antara sesama manusia, sebab dengan saling menghargai maka hubungan individu dengan orang lain akan semakin erat dan jauh dari rasa permusuhan dan kebencian (Abdullah, 2015).

Nilai Sipakatau, Sipakainge, Sipakalebbi merupakan nilai moral yang dapat diinternalisasikan dan diperkuat dalam keluarga dan masyarakat. Nilai tersebut juga sejalan dengan implementasi program anti-bullying. Saling menghormati, saling mengingatkan, dan saling menghargai sejalan dengan nilai karakter yang penting untuk mencegah individu untuk berpihak pada perilaku asosial dan amoral seperti bullying. Djuwita \& Mangunsong, (2016) menemukan bahwa nilai prososial yang dimiliki individu berperan penting dalam memuncukan efikasi diri dan keinginan bystander untuk membela korban pada situasi bullying. Berdasarkan hal tersebut, nilai budaya Sipakatau, Sipakainge, Sipakalebbi dapat menjadi faktor protektif yang ditanamkan pada bystander agar bertindak antibullying.

Dua prinsip yang sangat menentukan pola kehidupan manusia Bugis, yaitu; pertama, dalam setiap situasi, manusia harus menyadari kedudukan dirinya dan manusia lain sebagai persona (Tau). Setiap individu harus menempatkan dirinya sebagai Tau, sebagai makhluk yang kehidupannya paling mulia diantara makhluk lain, kedua menuntut bahwa manusia memiliki harkat dan martabat sehingga mampu memelihara, mempertahankan, dan memperjuangkan harkat dan martabat kemanusiaannya baik untuk dirinya maupun untuk orang lain dalam kedudukan sebagai makhluk sosial. Kedua prinsip hidup tersebut digunakan manusia Bugis sebagai landasan dalam berperilaku. Sejak anak terlahir, kedua prinsip tersebut telah ditanamkan dalam keluarga agar tindakannya menunjukkan dirinya 
sebagai persona, memperlakukan manusia lain juga sebagai persona (Tau Sipakatau), serta siap menegakkan harkat dan martabat manusia, baik untuk semua orang dalam cakupan dirinya sendiri, keluarga, negara, serta orang lain (Said, 2016).

Nilai saling memanusiakan dan menghormati orang lain dan memilik hak sama diperlakukan dengan baik merupakan prinsip utama pada kehidupan individu dari suku Bugis. Setiap individu harus menempatkan dirinya sebagai Tau, sebagai makhluk yang kehidupannya paling mulia diantara makhluk lain dan menuntut bahwa manusia memiliki harkat dan martabat sehingga mampu memelihara, mempertahankan, dan memperjuangkan harkat dan martabat kemanusiaannya baik untuk dirinya maupun untuk orang lain dalam kedudukan sebagai makhluk sosial. Prinsip tersebut telah ditanamkan dalam keluarga agar tindakannya menunjukkan dirinya sebagai persona dan memperlakukan manusia lain sebagai persona pula (Tau Sipakatau) serta siap menegakkan harkat dan martabat manusia, baik untuk dirinya sendiri, keluarga, negara, maupun orang lain (Said, 2016).

Prinsip Tau Sipakatau ditinjau penulis sangat bertolak belakang dengan konsep moral disengagement (dehumanisasi, atribusi korban) yang menyebabkan perilaku agresif dan perilaku pasif pada bystander bullying. Melalui prinsip 'Tau sipakatau' terbentuk nilai-nilai karakter yang disosialisasikan pada budaya Bugis, yakni Sipakatau, Sipakainge, Sipakalebbi.

Meningkatkan sensitifitas moral melalui Sipakatau, Sipakainge, Sipakalebbi dapat berkontribusi dalam memaksimalkan peran bystander dari pasif menjadi lebih aktif bertindak membela korban dan menghentikan tindak bullying. Berdasarkan pengambilan data awal yang dilakukan pada salah satu siswa SMA di kota Pare-Pare, ditemukan bahwa dalam pergaulan, menghargai orang lain adalah hal yang penting sebagai upaya individu ingin dihargai. Hal lain yang ditemukan adalah individu menganggap bullying tidak pantas dilakukan kepada siapapun termasuk kepada individu yang berbuat kesalahan. Thornberg \& Jungert (2013) menemukan bahwa sensitifitas moral terjadi pada individu yang bertindak membela korban pada situasi bullying.

Peran bystander sangat penting dalam menentukan berulang atau tidaknya bullying di sekolah sehingga dalam upaya pencegahan bullying perlu memaksimalkan peran bystander (Padgett \& Notar, 2013). Bullying terbentuk dari interaksi yang kompleks antara individu dan konteks dimana mereka berada, keluarga, teman sebaya, iklim sekolah, masyarakat, dan budaya. Setiap sistem yang berada di sekitar individu harus ditargetkan untuk program pencegahan dan penanganan bullying yang efektif (Swearer \& Hymel, 2015)

Bullying seringkali dicirikan oleh norma teman sebaya yang mendukung bullying dan tingginya konflik teman sebaya dan bahwa terjadi afiliasi dengan teman yang agresif (Swearer \& Hymel, 2015). Bullying menjadi upaya remaja untuk meningkatkan kekuasaan dan status dalam kelompok teman sebaya, sehingga, pelaku membutuhkan bystander dan pendukung (Salmivalli, 2014). Riset-riset tentang bullying berkembang menjadi fenomena kelompok yang menunjukkan kejadian bullying sebagai proses yang triadic. Hal tersebut mengacu pada konsep bahwa bullying melibatkan tiga pihak yang saling memengaruhi, dalam hal ini terdapat pelaku, korban, dan saksi yang kemudian dikenal dengan istilah bystander atau saksi. (Olweus; Rodkin \& Hodges; Salmivalli (Swearer \& Hymel, 2015)). Terdapat peran pelaku yang selalu pertama kali memulai serangan, diikuti oleh peran assistant yakni pihak yang membantu pelaku melancarkan aksinya, reinforcer, yakni pihak yang memberi penguatan pada pelaku dengan tertawa, bersorak, dsb, outsider sebagai pihak yang tidak bereaksi dan diam saja serta defender sebagai pihak yang membela. Participant role approach mengacu pada cara siswa terlibat dalam bullying, disamping korban, dan pelaku, anak-anak maupun remaja di kelas yang menyaksikan episode bullying yang memberikan efek pada episode bullying di sekolah (Salmivalli, 1999). Slaby (Padgett \& Notar, 2013) menjelaskan peran penting bystander disebabkan bystander dalam kelompok menjadi pemicu bullying, bahwa remaja sangat bergantung pada dukungan teman sebaya. Relasi pertemanan sebaya menjadi oksigen yang menjadikan bullying leluasa dan menyebar. Teman sebaya dapat menggunakan relasi tersebut sebagai senjata untuk menyasar dan menyerang korban yang tidak berdaya dalam kelompok namun meskipun satu teman yang baik berada di pihak korban, hal tersebut dapat membantu mengurangi konsekuensi yang menyakitkan ketika di-bully (Rodkin, 2012).

Bandura (Hymel \& Bonanno, 2014) mengemukakan teori Moral Agency, yang menjelaskan bahwa manusia adalah agen moral. Sejak kecil, anak-anak secara gradual mengembangkan kapasitas penalaran moral dan memperoleh standar perilaku moral yang membantu mereka untuk membedakan yang benar dan salah dan mengarahkan perilaku dalam budaya atau konteks dimana mereka berada. Standar moral dan penalaran moral dapat mengarahkan tindakan moral. Standar moral dan penalaran moral berkaitan dengan perilaku melalui mekanisme pengaturan diri. mekanisme ini dapat diaktifkan 
dan juga tidak diaktifkan atau dipisahkan dari standar moral pada situasi tertentu. Penjelasan tersebut juga digunakan untuk memahami tindakan amoril yang dilakukan oleh manusia pada situasi tertentu. Bystander pada situasi bullying cenderung menunjukkan sikap mendukung perilaku bullying dengan ikut tertawa, bersorak, ataupun dengan diam saja, akan memberikan penguatan diterimanya bullying oleh teman sebaya. Bystander ditemukan memiliki moral disengagement yang tinggi pada bystander yang berpihak pada pelaku maupun pada bystander yang pasif. Moral disengagement yang rendah berkaitan dengan perilaku anti-bullying seperti membela atau menunjukkan keberpihakan kepada korban (Barchia \& Bussey, 2011); (Carroll, 2014).

Berdasarkan teori Moral Agency yang dikemukakan oleh Bandura, dapat dijelaskan bahwa moral disengagement, merupakan mekanisme yang digunakan untuk membenarkan kejadian bullying di sekolah (Thornberg \& Jungert, 2014). Hal tersebut membuat bystander merasa tidak perlu membela korban karena kesalahan yang ada pada korban tersebut. Pentingnya menanamkan nilai moral untuk penguatan peran bystander akan membawa bystander melibatkan nilai-nilai moral yang tidak sesuai dengan bullying.

Jati diri manusia bugis dijabarkan dalam konstrak teoretis yang disusun oleh model Mattulada dan disusun oleh Said (2016) menekankan pada sadda, berupa bunyi yang dipandang khas dan memiliki nilai serta kekuatan yang dianggap luar biasa. Sadda menimbulkan dorongan yang kuat yang menampilkan pribadi yang teguh dalam menghadapi masalah kehidupan yang terjelma dalam sikap, perilaku, dan tempramen baik pada individu maupun kelompok.

Dua prinsip yang sangat menentukan pola kehidupan manusia Bugis, yaitu; pertama, dalam setiap situasi, manusia harus menyadari kedudukan dirinya dan manusia lain sebagai persona (Tau). Setiap individu harus menempatkan dirinya sebagai tau, sebagai makhluk yang kehidupannya paling mulia diantara makhluk lain, kedua menuntut bahwa manusia memiliki harkat dan martabat sehingga mampu memelihara, mempertahankan, dan memperjuangkan harkat dan martabat kemanusiaannya baik untuk dirinya maupun untuk orang lain dalam kedudukan sebagai makhluk sosial. kedua prinsip tersebut digunakan manusia Bugis sebagai landasan dalam berperilaku. Sejak anak terlahir, kedua prinsip tersebut telah ditanamkan dalam keluarga agar tindakannya menunjukkan dirinya sebagai persona dan memperlakukan manusia lain sebagai persona pula (Tau Sipakatau) serta siap menegakkan harkat dan martabat manusia, baik untuk dirinya sendiri, keluarga, negara, maupun orang lain.

Budaya sebagai sistem yang berdinamika pada aturan, eksplisit dan implisit, yang ditemukan dan dibuat oleh kelompok dengan tujuan untuk menjamin kelangsungan hidup, melibatkan sikap, nilai-nilai, keyakinan, norma dan perilaku yang disampaikan oleh kelompok namun dimiliki secara berbeda oleh berbagai unit spesifik dalam kelompok, dikomunikasikan lintas generasi, relatif stabil namun berpotensi mengalami perubahan dari waktu ke waktu. Matsumoto dan Juang menjelaskan bahwa sikap seseorang dipengaruhi oleh faktor budaya. Budaya merupakan sistem dinamis dengan aturan yang dimiliki oleh kelompok untuk menjamin keberlangsungan hidup, melibatkan sikap, nilai-nilai, keyakinan norma, dan perilaku (Arsela, Pohan, \& Djuwita, 2013).

(Amier, 2017) menyampaikan bahwa individu berinteraksi dalam masyarakat akan berusaha menjadi pribadi yang baik dan bertanggung jawab. Sifat tersebut menjadikan individu diterima oleh lingkungan sosialnya. Pergaulan dengan sesama manusia, diatur dalam pedoman bermasyarakat pada suku Bugis di Sulawesi Selatan melalui nilai Sipakatau, Sipakalebbi, Sipakainge.

Sipakatau adalah konsep yang memandang setiap manusia sebagai manusia seutuhnya, sehingga tidak pantas memperlakukan orang lain di luar perlakuan yang pantas bagi manusia. Konsep tersebut memandang manusia dengan segala penghargaannya. Siapapun, dengan kondisi sosial apapun, dengan kondisi fisik apapun yg dimilikinya, dia pantas diperlakukan selayaknya sebagai manusia beserta hakhak yang melekat padanya. Memandang orang lain sebagaimana individu memandang dirinya sebagai sesama manusia. Sipakalebbi mengacu pada konsep yang memandang manusia sebagai makhluk yang senang dipuji dan diperlakukan dengan baik dan layak. Sehingga manusia Bugis tidak akan memperlakukan manusia lain dengan seadanya, tapi cenderung memandang manusia dengan segala kelebihannya. Saling memuji akan menciptakan suasana yang menyenangkan dan menggairahkan, sehingga siapapun yang berada dalam kondisi tersebut akan senang dan bersemangat. Sipakainge, mengacu pada pengingatan apabila terjerumus atau tergoda atas perbuatan-perbuatan yang melanggar norma seperti korupsi atau maksiat. Saling mengingatkan menjadi penting terhadap kerabat, pasangan, atau sahabatnya. 
Sipakatau, Sipakalebbi, Sipakainge, menjadi modal dasar dalam tata hubungan manusia Bugis dengan manusia lain. Siri' yang merupakan kehormatan diri setiap manusia Bugis akan selalu dijaga dan dipertahankan dengan konsep Sipakatau, Sipakalebbi, Sipakainge (Amier, 2017). Nilai saling memanusiakan dan menghormati orang lain dan memilik hak sama diperlakukan dengan baik bertolak belakang dengan konsep moral disengagement (dehumanisasi, atribusi korban) yang menyebabkan perilaku pasif pada bystander (Almeida, Correia, \& Marinho, 2010; Doramarijan, 2014). Meningkatkan sensitifitas moral melalui Sipakatau, Sipakalebbi, Sipakainge diasumsikan dapat berkontribusi dalam memaksimalkan peran bystander dari pasif menjadi lebih aktif bertindak.

Pendekatan yang paling efektif untuk mencegah atau meminimalkan bullying melibatkan strategi multilevel yaitu untuk prevensi bullying melibatkan komponen sekolah untuk mengubah budaya dan iklim sekolah, kemudian level ruangan kelas strategi melibatkan guru dan orang dewasa lainnya di sekolah, kemudian pada level siswa, strategi didesain untuk menolong korban, pelaku dan bystander (Whitted \& Dupper, 2005). Swearer dan Doll (Hymel et al., 2005) mengemukakan perspektif ekologi sebagai upaya untuk memahami bagaimana bullying terjadi dengan melihat berbagai faktor ekologi, yang berinteraksi dan berhubungan langsung dengan individu, diantaranya keluarga, teman sebaya, sekolah, budaya, dan komunitas. Berdasarkan hal tersebut, penelitian ini bertujuan untuk mengetahui bagaimana nilai budaya Sipakatau, Sipakalebbi, Sipakainge diterapkan pada remaja Bugis sebagai bystander yang bertindak membela pada situasi bullying.

\section{Metode Penelitian}

\section{Partisipan}

Partisipan yang dilibatkan pada penelitian ini adalah siswa SMA di Kota Pare-Pare Sulawesi Selatan yang memiliki kriteria: 1) Bersuku Bugis, 2) Pernah menyaksikan bullying, 3) Mengetahui nilai Sipakatau, Sipakainge, Sipakalebbi 4) teridentifikasi berperan sebagai defender pada situasi bullying berdasarkan hasil screening dengan menggunakan peer nomination procedure. Jumlah partisipan pada penelitian ini adalah empat partisipan diperoleh melalui institusi sekolah melalui proses perijinan dan penentuan kelas ditentukan oleh pihak sekolah.

Prosedur Penelitian

Survei pengetahuan budaya Sipakatau, Sipakainge, Sipakalebbi, bullying vignette, dan sosiometri digunakan untuk screening terhadap 180 siswa SMA di Kota Parepare. Prosedur peer nomination dilakukan dengan membagikan lembaran absensi yang berisi nama setiap siswa dalam satu kelas. Setiap siswa diminta menilai peran semua teman kelas pada situasi bullying. Situasi bullying disediakan dalam bentuk bullying vignette berisi ilustrasi kejadian bullying yang menggambarkan lima peran berdasar literatur, yaitu bully, victim, assistant, reinfocer, outsider, defender. Partisipan yang sesuai dengan kriteria diundang untuk mengikuti wawancara. Berdasarkan kriteria yang ditentukan, peneliti memperoleh empat partisipan yang sesuai dan bersedia mengikuti wawancara. Guide wawancara semi terstruktur digunakan untuk menggali informasi terkait nilai Sipakatau, Sipakainge, Sipakalebbi, dan sejauhmana partisipan menerapkan nilai-nilai tersebut dalam pergaulan sehari-hari. Wawancara dilakukan terhadap siswa yang memenuhi kriteria defender bullying berdasarkan peer nomination dan self-report serta mengetahui Sipakatau, Sipakainge, Sipakalebbi

Metode Analisis Data

Penelitian ini menggunakan teknik wawancara mendalam semi terstruktur untuk menggali data mengenai nilai-nilai yang mendorong individu bertindak membela. Penelitian ini menggunakan kualitatif deskriptif. Analisis data dilakukan dengan kategorisasi data dengan melakukan koding dari pernyataan-pernyataan partisipan penelitian dan membuat tema-tema berdasarkan data. Hasil koding dilanjutkan dengan menggabungkan tema-tema kemudian diinterpretasikan. Keabsahan data dilakukan dengan melakukan triangulasi metode, yakni kesesuaian data berdasarkan metode, sumber, dan teori.

\section{Hasil Penelitian}

Berdasarkan penelitian yang telah dilakukan, diperoleh bahwa nilai Sipakatau, Sipakainge, Sipakalebbi disosialisasikan di lingkungan sekolah difasilitasi oleh OSIS di sekolah dan dalam keluarga. 
Nilai budaya Sipakatau, Sipakainge, Sipakalebbi, sejalan dengan nilai-nilai agama yang mendorong bystander membela pada situasi bullying. Konsep Sipakatau, Sipakainge, Sipakalebbi tidak secara langsung muncul dalam nilai budaya pada semua subjek, melainkan hanya pada partisipan ANS. Nilainilai yang muncul dalam pergaulan terhadap sesama manusia muncul sebagai pendorong individu bersikap menghormati, menghargai, dan mengingatkan yang didorong oleh nilai-nilai agama.

Konsep Sipakatau muncul dalam respon menghormati orang lain yang ditunjukkan dengan sikap dan tutur kata.

"Misalnya kalo Nabi Muhammad, kalo beliau itu dipanggil, seluruh tubuhnya berbalik, bukan cuma kepalanya berbalik."(MAW)

"Kalo saya kak ambil dari pengalaman pribadi ji kalo misalnya kak ada orang nda kusuka caranya bicara jadi tidak mauka seperti orang seperti begitu.. bemana caramu mau ajak bicara orang kalo orang yang koajak bicara itu,..ee enek.."(MAW)

itu anu kak lingkungan keluarga ku kayak agak segan untuk singgung orang lain.. kayak lingkunganku yang tuntutka begitu sama orang.. (ANS)

Konsep saling mengingatkan muncul dalam respon menegur pelaku dengan pendekatan personal (indirect) dan strategi komunikasi pada pelaku maupun korban.

"Kayak tidak enak, nda enak juga ditegur secara langsung to kak. Jadii mencobaka seaplikatif mungkin mengaplikasikan pengalamanku supaya bisaki berkomunikasi dengan baik, tidak ada dendam, tidak ada pembicaraan di belakang, kita hindari supaya tidak ada fitnah dan lainlain. (MAW)

"Biasaji kutanyaji bilang we janko kasi begitu orang, kalau misalnya too emm nalakukan begitu to biasaji kutanya kak kenapa je, apa gunamu kasih begituii... tidak adaji juga salahnya sama kau, nda naapa apai jeko, kauji yang salah. (GP)

"toh haruski memang satu kelas saling mengingatkan bilang jangan kasi begitui to, dikasi ingat saja begitu kak.. ditanyai jangko berlebihan begitu, musakiti fisiknya mulempari bola begitu baru musinggung singgung perasaannya siapa nda sakit kalo begitu”(GP)

"Saya tidak pernah menegur langsung pada kejadiannya kak, karena menurut saya itu tidak akan menyelesaikan masalah bahkan berulang kembali. (MF)

Jadi saya lakukan pendekatan langsung, jadi tidak ada orang lain.. jadi saya tidak.. nda umbar juga aibnya pelaku...(MF)

Konsep saling menghargai atau Sipakalebbi dalam pergaulan, muncul dalam respon bersikap dan bertutur sopan, menyesuaikan cara berkomunikasi dengan lawan bicara.

"Bagaimana kita bertutur kata bagaimana kita e sopan dalam bertindak, e pikir dahulu sebelum mengutarakan atau melakukan sesuatu dan yaa kita harus menghargai orang lain уаа,,"(MAW)

Hal terbaik adalah juga menjaga perasaan pelaku meskipun dia bersalah karena apabila perasaan pelaku terluka, dia juga akan berdampak pada saya dan akan lebih parah kepada yang jadi korban.. (MF)

\section{Pembahasan}

Penelitian ini dilakukan dengan tujuan untuk mengetahui bagaimana nilai Sipakatau, Sipakainge, Sipakalebbi diterapkan pada individu yang bertindak membela pada situasi bullying. Berdasarkan hasil yang diperoleh melalui wawancara, ditemukan bahwa nilai saling menghargai, mengingatkan, dan menghormati muncul dalam pergaulan sesama teman bersumber dari nilai-nilai agama. Nilai prososial 
dalam konsep Sipakatau, Sipakainge, Sipakalebbi muncul pada upaya maupun strategi yang digunakan individu untuk melakukan tindakan pencegahan bullying. Konsep Sipakatau muncul dalam respon menghormati orang lain yang ditunjukkan dengan sikap dan perkataan. Sikap menghormati dijelaskan oleh partisipan dengan menyesuaikan diri dan perkataan terhadap lawan bicara. Partisipan berkomunikasi dengan baik ditunjukkan dengan menyesuaikan intonasi ketika berhadapan dengan orang yang berasal dari suku lain. Komunikasi yang baik juga ditunjukkan dengan perkataan baik yang bisa diterima orang lain tanpa membuat orang lain merasa tidak dihargai. Partisipan ANS menunjukkan konsep Sipakatau dengan menjaga sikap terhadap orang lain dan segan untuk melakukan sesuatu yang dianggap mengganggu orang lain.

Konsep Sipakainge atau saling mengingatkan muncul dalam respon menegur pelaku dengan pendekatan personal (indirect) dan strategi komunikasi pada pelaku maupun korban. Partisipan MW dan MF mengungkapkan bahwa mengingatkan teman lain yang berbuat kesalahan dalam hal ini 'pengganggu' harus dilakukan. Strategi komunikasi dilakukan partisipan dalam penelitian ini untuk upaya menghentikan perilaku bullying. Strategi komunikasi dengan pendekatan personal ditunjukkan dalam perilaku menegur pengganggu satu persatu, tidak secara bersamaan dan tidak pula di depan teman-teman.

Konsep Sipakalebbi atau saling menghargai dalam pergaulan, muncul dalam respon bersikap dan bertutur sopan, menyesuaikan cara berkomunikasi dengan lawan bicara. Partisipan MAW menekankan bahwa berpikir sebelum bertindak menjadi cara untuk menghargai orang lain. Partsipan MF menekankan pentingnya menjaga perasaan pengganggu sekalipun orang tersebut salah.

Bandura (Hymel \& Bonanno, 2014) mengemukakan teori Moral Agency, yang menjelaskan bahwa manusia adalah agen moral. Sejak kecil, anak-anak secara gradual mengembangkan kapasitas penalaran moral dan memperoleh standar perilaku moral yang membantu mereka untuk membedakan yang benar dan salah dan mengarahkan perilaku dalam budaya atau konteks dimana mereka berada. Standar moral dan penalaran moral dapat mengarahkan tindakan moral. Matsumoto dan Juang (Djuwita \& Mangunsong, 2016) mengemukakan bahwa orang Indonesia merupakan bagian dari masyarakat kolektif. Sebagai bagian dari masyarakat kolektif, orang Indonesia memiliki kecenderungan untuk mendasarkan pada nilai-nilai kelompok, termasuk dalam kecenderungan prososial. Djuwita \& Mangunsong (2016) menemukan bahwa nilai prososial individu untuk membela pada situasi bullying dimediasi oleh efikasi kolektif. (Forsberg et al., 2018)menemukan bahwa ekspektasi bystander terhadap diri sendiri dan orang lain menjadi motif individu untuk membela korban bullying. Ekspektasi untuk mampu membela dan efikasi diri membela, serta ekspektasi terhadap bystander lain yang memengaruhi ekspektasi diri untuk membela pada situasi bullying. Berdasarkan hal tersebut dapat dijelaskan bahwa nilai yang berlaku dalam kelompok berperan dalam membentuk perilaku dalam menghadapi situasi sosial dalam masyarakat.

Nilai-nilai agama yang mengajarkan individu bersikap baik dan menolong orang lain, ditinjau sejalan dengan nilai-nilai budaya yang disosialisasikan dalam masyarakat. Berdasarkan hal tersebut, dapat dijelaskan bahwa perilaku membela pada situasi bullying dapat ditingkatkan dengan mensosialisasikan nilai-nilai pergaulan dalam ajaran agama dan nilai-nilai pergaulan dalam masyarakat dimana individu berada.

Partisipan MAW dan MF merupakan figur pengurus organisasi keagamaan di sekolah. Berdasarkan informasi yang diperoleh dari teman kelas, diketahui bahwa MAW merupakan figur yang disukai dan didengarkan di kelas. MAW juga merupakan figur yang dikagumi pribadinya oleh teman sebaya. Partisipan GP merupakan figur yang disukai di kelas sebab lebih pintar dan bersedia berteman dengan siapa saja. GP merupakan figur yang diterima dalam kelompok teman sebaya karena GP sering membantu teman yang kesulitan mengerjakan tugas sekolah Berdasarkan literatur, defender atau pembela memiliki karakteristik tertentu, seperti social rank dalam kelompok sebaya (Thornberg et al., 2012). Popularitas dan preferensi teman sebaya memengaruhi perilaku defender (Yun, 2020). Defender perlu memiliki popularitas di kalangan sebaya yang lebih tinggi dari pelaku bully agar perilaku membela dapat efektif dan tidak berisiko (Hessel, 2019). Temuan ini mengindikasikan bahwa figur yang dinilai memiliki karakter positif dan social rank yang tinggi dalam kelompok sebaya perlu dilibatkan sebagai agen prevensi bullying di sekolah. Implikasinya adalah pengurus organisasi osis maupun rohis perlu dilibatkan dalam mensosialisasikan nilai Sipakatau, Sipakainge, Sipakalebbi dan diimplementasikan dalam berbagai kegiatan sekolah. 


\section{Kesimpulan}

Berdasarkan hasil penelitian ini, ditemukan beberapa hal, pertama nilai Sipakatau, Sipakainge, Sipakalebbi merupakan strategi yang digunakan individu bertindak membela pada situasi bullying. Kedua, nilai yang muncul dalam pergaulan individu adalah nilai prososial yang bersumber dari ajaran agama dan nilai budaya. Ketiga temuan lainnya bahwa individu pembela yang menerapkan Sipakatau, Sipakainge, Sipakalebbi adalah figur yang disukai oleh teman sebaya. Temuan ini dapat menjadi masukan untuk mempromosikan nilai-nilai pergaulan berbasis agama dan budaya sebagai pencegahan bullying, salah satunya adalah nilai Sipakatau, Sipakainge, Sipakalebbi.

\section{Ucapan Terima Kasih}

Penelitian ini merupakan penelitian yang didanai oleh dana PNBP Fakultas Psikologi Universitas Negeri Makassar Tahun 2019

\section{Daftar Pustaka}

Abdullah. (2015). Falsafah hidup orang bugis Makassar yang sarat nilai-nilai pembelajaran. https://www.kompasiana.com/171717/54f341d4745513a32b6c6db2/falsafah-hidup-orang-bugismakassar-yang-sarat-nilainilai-pembelajaran

Almeida, Correia, M. (2010). Moral disengagement, normative beliefs of peer group, and attitudes regarding roles in bullying. Journal of School Violence, 2, 23-36. https://doi.org/10.1080/15388220903185639

Amier. (2017). Mengamalkan nilai-nilai sipakatau, sipakalebbi, dan sipakainge. http://phinisi.co/index.php/2017/12/06/mengamalkan-nilai-nilai-sipakatau-sipakalebbi-dansipakainge/

Amnda, V., Wulandari, S., Wulandari, S., Syah, S. N., Restari, Y. A., Atikah, S., Engkizar, E., Anwar, F., \& Arifin, Z. (2020). Bentuk Dan Dampak Perilaku Bullying Terhadap Peserta Didik. Jurnal Kepemimpinan Dan Pengurusan Sekolah, 5(1), 19-32.

Barchia, K., \& Bussey, K. (2011). Predictors of student defenders of peer aggression victims: Empathy and social cognitive factors. International Journal of Behavioral Development, 35(4), 289-297.

Carroll, H. L. (2014). Social cognitive factors associated with verbal bullying and defending. Wayne State University.

Djuwita, R., \& Mangunsong, F. M. (2016). Links between prosocial value and bystanders' helping behavior in bullying situation: The mediating role of collective efficacy and psychological well-being as moderator. The Asian Conference on Psychology and the Behavioral Sciences.

Doramarijan. (2014). Determinant of bystander behaviour during school bullying: the role of moral disengagement, personality, dan friendship. Concordia University Canada.

Forsberg, C., Wood, L., Smith, J., Varjas, K., Meyers, J., Jungert, T., \& Thornberg, R. (2018). Students' views of factors affecting their bystander behaviors in response to school bullying: a crosscollaborative conceptual qualitative analysis. Research Papers in Education, 33(1), 127-142.

Halimah, A., Khumas, A., \& Zainuddin, K. (2015). Persepsi pada By stander terhadap Intensitas Bullying pada Siswa SMP. Jurnal Psikologi, 42(2), 129-140.

Hessel, K. (2019). Who Should Defend Victims of Bullying? The Effects of Relative Status on Defender and Victim Outcomes.

Hymel, S., \& Bonanno, R. A. (2014). Moral disengagement processes in bullying. Theory into Practice, $53(4), 278-285$.

Hymel, S., Rocke-Henderson, N., \& Bonanno, R. A. (2005). Moral disengagement: A framework for understanding bullying among adolescents. Journal of Social Sciences, 8(1), 1-11.

KPAI.go.id. (2020). Sejumlah kasus Bullying sudah warnai catatan kekerasan anak di awal 2020, begini kata komisioner KPAI. https://www.kpai.go.id/publikasi/sejumlah-kasus-bullying-sudah-warnaicatatan-masalah-anak-di-awal-2020-begini-kata-komisioner-kpai

Lynn Hawkins, D., Pepler, D. J., \& Craig, W. M. (2001). Naturalistic observations of peer interventions in bullying. Social Development, 10(4), 512-527.

Padgett, S., \& Notar, C. E. (2013). Bystanders Are the Key to Stopping Bullying. Universal Journal of Educational Research, 1(2), 33-41. 
Rodkin, P. C. (2012). Bullying and children's peer relationships. Colleagues, $8(2), 4$.

Said, M. (2016). Jati diri manusia Bugis. Pro Deleader.

Salmivalli, C. (1999). Participant role approach to school bullying: Implications for interventions. Journal of Adolescence, 22(4), 453-459.

Salmivalli, C. (2014). Participant roles in bullying: How can peer bystanders be utilized in interventions? Theory Into Practice, 53(4), 286-292.

Swearer, S. M., \& Hymel, S. (2015). Understanding the psychology of bullying: Moving toward a socialecological diathesis-stress model. American Psychologist, 70(4), 344.

Tempo.co.id. (2018). No Title. https://www.google.com/amp/1109584/hari-anak-nasional-kpai-catat-kasusbullying-paling-banyak

Thornberg, R., \& Jungert, T. (2013). Bystander behavior in bullying situations: Basic moral sensitivity, moral disengagement and defender self-efficacy. Journal of Adolescence, 36(3), 475-483.

Thornberg, R., \& Jungert, T. (2014). School bullying and the mechanisms of moral disengagement. Aggressive Behavior, 40(2), 99-108.

Thornberg, R., Tenenbaum, L., Varjas, K., Meyers, J., Jungert, T., \& Vanegas, G. (2012). Bystander motivation in bullying incidents: To intervene or not to intervene? Western Journal of Emergency Medicine, 13(3), 247.

Whitted, K. S., \& Dupper, D. R. (2005). Best practices for preventing or reducing bullying in schools. Children \& Schools, 27(3), 167-175.

Yun, H. (2020). New approaches to defender and outsider roles in school bullying. Child Development, 91(4), e814-e832.

Zakiyah, E. Z., Fedryansyah, M., \& Gutama, A. S. (2018). Dampak bullying pada tugas perkembangan remaja korban bullying. Focus: Jurnal Pekerjaan Sosial, 1(3), 265-279. 